\title{
ComparativeEvaluation of Oxidative Stress in Type-2 Diabetes Mellitus in Relation to Controlled Vs Uncontrolled Diabetes
}

\author{
Aisha Beg ${ }^{1}$, Rajesh Kumar Thakur ${ }^{1}$, Rahul Saxena ${ }^{3}$, Gladys Rai', \\ Saurabh Srivastava ${ }^{2}$ and Jasvinder K Gambhir ${ }^{1 *}$ \\ ${ }^{1}$ Departments of Biochemistry1\& Medicine2, School of Medical Sciences and Research, Sharda University, \\ Knowledge Park-III, Greater Noida, U.P-India. \\ ${ }^{2}$ Departments of Medicine2, School of Medical Sciences and Research, Sharda University, Knowledge Park-III, \\ Greater Noida, U.P-201306. \\ ${ }^{3}$ Department of Biochemistry3,School of Allied Health Sciences, Sharda University, Knowledge Park-III, \\ Greater Noida, U.P-201306.
}

\begin{abstract}
Background: Type 2 Diabetes Mellitus (T2DM)is associated with the production of excess free radicals which are not neutralised by available antioxidants thereby,leading to oxidative stress(OS).The extent of oxidative damage and resulting diabetic complications may be determined by the degree of hyperglycemia viz; controlled vs uncontrolled T2DM.

Aim: To evaluate and compare oxidative stress in T2DM patients with good glycemic control vs uncontrolled T2DM,by estimatingmalondialdehyde (MDA,index of lipid peroxidation), ferric acid reducing ability of plasma (FRAP as total antioxidant capacity,TAC).

Methods: The study included 50 healthy controls(Gp I)and 100 T2DM patients which were further divided into:Gp II having good glycemiccontrol $(\mathrm{HbAlc} \leq 7.0 \%)$ andGp IIIwith uncontrolled T2DM $(\mathrm{HbAlc}>7.0 \%)(\mathrm{n}=50$ each). Fasting \& post-prandial plasma glucose, HbA1c, MDA, FRAP\&hsCRPwere estimated using standard methods.

Result: MDA was significantly higher and FRAP was significantly lower in T2DM patients as compared to healthy controls. Further, T2DM patients(Gp III) with uncontrolled hyperglycemia had higher degree of oxidative stress vs Gp II patients with good glycemic control.Moreover there was:i)A significant positive correlation between HbA1c \& MDA ( $<<0.001)$, \& ii) Significant negative correlation betweenHbA1c\& FRAP and MDA\& FRAP $(\mathrm{p}<0.001)$ in T2DM patients.

Conclusion: Oxidative stress in T2DM patients is directly proportional to the degree of hyperglycemia measured as HbA1c.Therefore it is important tomaintaintight glycemic control in T2DM patients(HbA1c $\leq 7 \%$ ), to decrease oxidative stress and thereby delay the onset of diabetic complications.
\end{abstract}

Keywords: Oxidative Stress;Type 2 Diabetes Mellitus; Hba1c; Malondialdehyde; Frap

\section{Introduction}

Diabetes mellitus (T2DM) is characterized by prolonged hyperglycemia either due to progressive decrease in insulin secretion and /or insulin resistance. According to International Diabetic Federation (IDF) approximately 285 million (6.6\%) world population had DM in 2010, which is projected to increase to 438 million $(7.8 \%)$ by $2030^{[1]}$ T2DM is one of the most challenging and serious global health problem of the century leading to considerable morbidity and mortality.

In T2DM there are disturbances in carbohydrate, protein and lipid metabolism which are evident even in prediabetic state. Further, chronic hyperglycemia in T2DM leads to increased production of free radicals, especially reactive oxygen species (ROS) due to glucose autooxidation, polyol pathway and non-enzymatic glycation of proteins ${ }^{[2]}$. The imbalance between the rate of free radical generation and their elimination due to decrease in the available antioxidant mechanisms leads to oxidative stress(OS), which is ultimately linked to the manifestation of macro and micro-vascular complications ${ }^{[3]}$.

An increase in free radicals causes overproduction of malondialdehyde (MDA), which is a biomarker of oxidative damage to lipids ${ }^{[4]}$. On the other hand, ferric acid reducing ability of plasma (FRAP) is a measure of the total antioxidant capacity of plasma ${ }^{[5]}$. Another important consequence of hyperglycemia induced ROS generation is the activation of pro-inflammatory cascade which inturn results in increased hsCRP levels, a marker of inflammation. Glycosylated hemoglobin (HbAlc) is considered an integrated and reproducible measure of the long term glycemic contol. It is expressed as a percentage 
of glycosylated $\mathrm{Hb}$ relative to total $\mathrm{Hb}$ in blood with normal range of 4.0-6.0\%. HbA1c reflects average plasma glucose over the previous $8-12$ weeks $^{[6]}$. Therefore, HbA1c levels are useful in the long-term monitoring and management of T2DM. Depending on the targets for glycemic control , as recommended by the American Diabetes Association (ADA) Clinical Practice Guidelines [7], diabetic patients can be divided on the basis of HbA1c cut-off value of $\leq 7.0$ $\%$ vs $>7.0 \%$ into patients with good glycemic control vs uncontrolled DM, respectively. Therefore the overall objective of the present study was to evaluate and compare oxidative stress in T2DM patients by evaluating MDA \& FRAP levels in relation to glycemic control i.e.HbA1c $\leq$ $7.0 \%$ vs $>$ than $7.0 \%$.

\section{Materials and Methods}

Study Design; This case-control study was conducted on 50 healthy subjects and 100 diabetic patients, which were further divided into patients having controlled vs uncontrolled diabetes depending on $\mathrm{HbAlc}$ values as follows: Group I (healthy control group): comprised of 50 healthy individuals selected from the staff of SMS\&R and unrelated attendants of patients of either sex. Group II (controlled T2DM): comprised of 50 T2DM patients having HbA $1 \mathrm{c} \leq 7.0 \%$. Group III (uncontrolled T2DM): comprised of $50 \mathrm{~T} 2 \mathrm{DM}$ patients having $\mathrm{HbA} 1 \mathrm{c}>7.0 \%$. The present study was conducted at the School of Medical Sciences \& Research (SMS\&R) in the Departments of Biochemistry and Medicine ,SMS \& R, Sharda University, Greater Noida. This study was approved by the Institutional Ethics Committee for Human Research. Informed written consent was obtained from each participant, after explaining the purpose of this study in their own language, before the initiation of the study.

Participant's Selection: Participants were selected \& diagnosed on the basis of history, clinical examination and laboratory investigations. The study included non-smokers of either sex in the age group of $30-60$ years. Exclusion criteria were age $<30$ yrs $\&>60 y r s$, smokers and pregnant women.

Collection of Blood Sample: Blood samples were collected from the selected participants from midcubital vein after taking aseptic precautions; approx $1 \mathrm{ml}$ blood in fluoride vacutainer, $4 \mathrm{ml}$ in EDTA vacutainer and $2 \mathrm{ml}$ in plain vacutainer after 10-12 hrs of overnight fasting, the participants were asked to take breakfast and postprandial blood sample was collected after $2 \mathrm{hrs}$. Vacutainers were centrifuged at $2000 \mathrm{rpm}$ for 5 minutes to obtain serum or plasma.

Biochemical Investigations: $\mathrm{HbA1c}$ was estimated in whole blood (K2-EDTA vacutainer) on Bio-Rad D-10 by NGSP certified method which utilizes principle of ion-exchange high performance liquid chromatography (HPLC). Routine biochemical parameters were analysed on the Semi Autoanalyser Rapid Star 21 plus by the following methods: Fasting \& PP plasma glucose was estimated by GOD-POD method, ${ }^{[8]}$ serum urea by urease/glutamate dehydrogenase (GLDH) method ${ }^{[9]} \&$ serum creatinine by Jaffe's method as modified by Cook ${ }^{[10]}$, cholesterol by CHOD-POD method [11] ,triglycerides by GPO method ${ }^{[12]}$, HDL-C by phosphotungstic acid method ${ }^{[13]}$. VLDL-C $\&$ LDL-C were calculated by Friedwald's formula ${ }^{[14]}$. Lipid peroxidation was assessed by measuring plasma malondialdehyde (MDA) by Satoh's method ${ }^{[15]}$ and total antioxidant capacity (TAC) as ferric reducing ability of plasma (FRAP) by Benzie et al ${ }^{[5]}$. Estimation of Inflammatory marker, high-sensitivity $\mathrm{C}$-reactive protein (hsCRP) was done by solid phase sandwich ELISA using commercially available kits from Calbiotech diagnostics (USA).

Statistical Analysis: For statistical analysis SPSS 17 was used. Values are expressed as mean $\pm \mathrm{SD}$. For comparison of parametric analytes student's t-test was used \& $\mathrm{p} \leq 0.05$ was taken as significant. Association between different variables was carried out by using Pearson's correlation.

\section{Results}

Baseline demographic and renal profile of study groups are shown in Table 1 . There were no significant differences in mean age, male/female ratio and BMI between different study groups. Serum urea and creatinine were also within normal range in all the groups. Table -2 shows the glycemic profile of different study groups. There was a 1.5 -fold and 2.5-fold increase in plasma glucose levels (F \& PP) in Gp II and Gp III, respectively $(\mathrm{p}<0.001)$ as compared to healthy controls. HbA1c levels were significantly higher in T2DM Gp II $(p<0.05)$, which were further increased in Gp III (uncontrolled T2DM,p $<0.001$ ) vs healthy controls, thereby suggesting that as the glucose levels increase the percentage of $\mathrm{HbAlc}$ also increases.

Lipid profile parameters in patients and control groups are compared in Table- 3, there were no significant differences in triglycerides (TG), total cholesterol (TC), LDL- cholesterol (LDL- C) and VLDL-cholesterol (VLDL-C) between Gp I and Gp II whereas, HDL cholesterol (HDL-C) was significantly lower $(\mathrm{p}<0.001)$. However, in GpIII (uncontrolled T2DM), TG, TC, LDL-C and VLDL-C were significantly higher, whereas HDL-C was significantly lower as compared to $\mathrm{HC}$ and $\mathrm{Gp}$ II $(\mathrm{p}<0.001)$. These observations suggest that diabetes leads to disturbances in lipid metabolism, which may be a risk factor for coronary artery disease. 
As shown in Table - 4 MDA and hsCRP were significantly higher in Gp II in comparison to Gp I (HC), whereas these were further increased in Gp III as compared to Gp II (controlled vs uncontrolled DM, $\mathrm{p}<0.001$ ). FRAP was significantly lower in Gp II vs Gp I, which was further decreased in Gp III $(p<0.001)$. Therefore, the results of these parameters suggest that in diabetes there is increased oxidative stress. However, in case of good glycemic control the disturbances in these parameters are milder as compared to patients with uncontrolled T2DM. Table-5 shows the correlation between HbA1c, FRAP and MDA. There is a significant negative correlation between $\mathrm{HbA} 1 \mathrm{c}$ \& FRAP, and a positive correlation between HbA1c \& MDA. Further, there is a significant negative correlation between MDA and FRAP. These results suggest that in T2DM increase in free radicals is directly proportional to the degree of hyperglycemia with a corresponding decrease in antioxidant capacity.

Table 1: Baseline demographic and renal profile of study groups.

\begin{tabular}{|c|c|c|c|}
\hline Parameters & $\begin{array}{c}\text { Gp I } \\
(\mathbf{n = 5 0 )}\end{array}$ & $\begin{array}{c}\text { Gp II } \\
(\mathbf{n = 5 0 )}\end{array}$ & $\begin{array}{c}\text { Gp III } \\
(\mathbf{n = 5 0 )}\end{array}$ \\
\hline Age (years) & $43.9 \pm 6.5$ & $46.4 \pm 8.5$ & $47.5 \pm 7.2$ \\
\hline Male / female Ratio & $27 / 23$ & $26 / 24$ & $28 / 22$ \\
\hline BMI $(\mathrm{kg} / \mathrm{m} 2)$ & $22.1 \pm 1.7$ & $23.3 \pm 1.5$ & $23.7 \pm 1.8$ \\
\hline Serum urea $(\mathrm{mg} / \mathrm{dL})$ & $27.2 \pm 4.5$ & $29.8 \pm 6.1$ & $31.2 \pm 6.7$ \\
\hline Serum creatinine(mg/dL) & $0.75 \pm 0.16$ & $0.77 \pm 0.20$ & $0.79 \pm 0.27$ \\
\hline
\end{tabular}

Data are expressed as mean $+S D$.

BMI: Body Mass Index

Table 2: Plasma Glucose profile of different study groups.

\begin{tabular}{|c|c|c|c|}
\hline Parameters & $\begin{array}{c}\text { Gp I } \\
(\mathbf{n = 5 0 )}\end{array}$ & $\begin{array}{c}\text { Gp II } \\
(\mathbf{n = 5 0 )}\end{array}$ & $\begin{array}{c}\text { Gp III } \\
(\mathbf{n = 5 0 )}\end{array}$ \\
\hline $\begin{array}{c}\text { Plasma glucose } \\
\text { Fasting (mg/dL) }\end{array}$ & $90.5 \pm 10.2$ & $140.5 \pm 4.5^{\mathrm{a}}$ & $259.9 \pm 20.6^{\mathrm{a}, \mathrm{b}}$ \\
\hline $\begin{array}{c}\text { Plasma glucose } \\
\text { Postprandial(mg/dL) }\end{array}$ & $124.8 \pm 13.6$ & $182.7 \pm 12.1^{\mathrm{a}}$ & $311.9 \pm 23.2^{\mathrm{a}, \mathrm{b}}$ \\
\hline $\mathrm{HbA1c}(\%)$ & $5.7 \pm 0.35$ & $6.8 \pm 0.25^{\mathrm{c}}$ & $9.4 \pm 2.8^{\mathrm{a}, \mathrm{b}}$ \\
\hline
\end{tabular}

Data are expressed as mean $+S D$.

${ }^{a} p<0.001$ vs GPI

${ }^{b} p<0.001$ vs GpII

${ }^{c} p<0.05$ vs GPIII

Table 3: Lipid profile parameters in patients and control groups.

\begin{tabular}{|c|c|c|c|}
\hline Parameters & $\begin{array}{c}\text { Gp I } \\
(\mathbf{n = 5 0 )}\end{array}$ & $\begin{array}{c}\text { Gp II } \\
(\mathbf{n = 5 0 )}\end{array}$ & $\begin{array}{c}\text { Gp III } \\
(\mathbf{n = 5 0 )}\end{array}$ \\
\hline Triglyceride & $141.63 \pm 10.9$ & $142.5 \pm 13.3$ & $199.1 \pm 25.2^{\mathrm{a}, \mathrm{b}}$ \\
\hline Total Cholesterol & $170.6 \pm 22.2$ & $180.5 \pm 30.1$ & $257.0 \pm 27.1^{\mathrm{a}, \mathrm{b}}$ \\
\hline HDL- C & $40.4 \pm 5.1$ & $34.4 \pm 5.6^{\mathrm{a}}$ & $32.5 \pm 6.1^{\mathrm{a}}$ \\
\hline LDL- C & $102.4 \pm 16.4$ & $118.1 \pm 17.2$ & $185.9 \pm 29.7^{\mathrm{a}, \mathrm{b}}$ \\
\hline VLDL-C & $27.8 \pm 2.6$ & $28.1 \pm 2.8$ & $39.8 \pm 5.9^{\mathrm{c}}$ \\
\hline
\end{tabular}

Data are expressed as mean $+S D$.

HDL-C: High Density Lipoprotein-Cholesterol; LDL-C: Low Density Lipoprotein-Cholesterol; VLDL-C: Very Low Density Lipoprotein-Cholesterol

${ }^{a} p<0.001$ vs GpI

${ }^{b} p<0.001$ vs GpII

${ }^{c} p<0.05$ vs GpIII 
Table 4: MDA, FRAP and hsCRP in control and patient groups.

\begin{tabular}{|c|c|c|c|}
\hline Parameters & $\begin{array}{c}\text { Gp I } \\
(\mathbf{n = 5 0 )}\end{array}$ & $\begin{array}{c}\text { Gp II } \\
(\mathbf{n = 5 0 )}\end{array}$ & $\begin{array}{c}\text { Gp III } \\
(\mathbf{n = 5 0})\end{array}$ \\
\hline MDA $(\mathrm{nmol} / \mathrm{ml})$ & $1.90 \pm 0.47$ & $2.60 \pm 0.35 \mathrm{c}$ & $6.8 \pm 0.48 \mathrm{a}, \mathrm{b}$ \\
\hline FRAP $(\mu \mathrm{mol} / \mathrm{L})$ & $407.6 \pm 51.6$ & $307.6 \pm 45.62 \mathrm{a}$ & $142.6 \pm 26.5 \mathrm{a}, \mathrm{b}$ \\
\hline $\mathrm{hsCRP}(\mathrm{mg} / \mathrm{L})$ & $0.74 \pm 0.46$ & $3.67 \pm 1.46 \mathrm{a}$ & $5.49 \pm 1.65 \mathrm{a}, \mathrm{b}$ \\
\hline
\end{tabular}

Data are expressed as mean $\pm S D$.

FRAP: Ferric Reducing Ability of Plasma , MDA: Malondialdehyde, hsCRP: High Sensitive C-Reactive Protein

${ }^{a} p<0.001$ vs $\mathrm{GPI}$

${ }^{b} p<0.001$ vs GpII

${ }^{c} p<0.05$ vs GpIII

Table 5: Pearson's correlation between HbA1c, FRAP \& MDA in T2DM patients.

\begin{tabular}{|c|c|c|}
\hline & HbA1c & FRAP \\
\hline $\begin{array}{c}\text { HbA1c Pearsons Correlation } \\
\text { Sig (2-tailed) } \\
\text { N }\end{array}$ & $\begin{array}{c}1 \\
78\end{array}$ & $\begin{array}{c}-0.730^{* *} \\
0.000 \\
78\end{array}$ \\
\hline \multirow[t]{2}{*}{$\begin{array}{c}\text { FRAP Pearsons Correlation } \\
\text { Sig (2-tailed) } \\
\text { N }\end{array}$} & $\begin{array}{l}-0.730^{* *} \\
0.000 \\
78\end{array}$ & $\begin{array}{l}1 \\
78 \\
\end{array}$ \\
\hline & $\mathrm{HbA1c}$ & MDA \\
\hline $\begin{array}{c}\text { HbA1c Pearsons Correlation } \\
\text { Sig (2-tailed) } \\
\mathrm{N}\end{array}$ & $\begin{array}{l}1 \\
78\end{array}$ & $\begin{array}{l}0.784^{\star \star *} \\
0.000 \\
78\end{array}$ \\
\hline \multirow[t]{2}{*}{$\begin{array}{c}\text { MDA Pearsons Correlation } \\
\text { Sig (2-tailed) } \\
\text { N }\end{array}$} & $\begin{array}{l}0.784^{* * *} \\
0.000 \\
78\end{array}$ & $\begin{array}{c}1 \\
78\end{array}$ \\
\hline & FRAP & MDA \\
\hline $\begin{array}{c}\text { FRAP Pearsons Correlation } \\
\text { Sig (2-tailed) } \\
\mathrm{N}\end{array}$ & $\begin{array}{l}1 \\
78 \\
\end{array}$ & $\begin{array}{l}-0.947^{* * * *} \\
0.000 \\
78\end{array}$ \\
\hline $\begin{array}{c}\text { MDA Pearsons Correlation } \\
\text { Sig (2-tailed) } \\
\mathrm{N}\end{array}$ & $\begin{array}{c}-0.947^{* * * *} \\
0.000 \\
78\end{array}$ & $\begin{array}{l}1 \\
78\end{array}$ \\
\hline
\end{tabular}

${ }^{* *}$ Correlation is significant at the 0.01 level (2-tailed)

${ }^{* * * *}$ Correlation is significant at the 0.01 level (2-tailed).

${ }^{* * * * *}$ Correlation is significant at the 0.01 level (2-tailed).

FRAP: Ferric Reducing Ability of Plasma, MDA: Malondialdehyde, hsCRP: High Sensitive C-Reactive Protein

\section{Discussion}

Type 2 diabetes mellitus is a chronic lifestyle disorder leading to metabolic abnormalities. Chronic hyperglycemia in T2DM is associated with the production of excess free radicals, which accumulate in blood and tissues resulting in oxidative stress which promotes both macro and microvascular complications ${ }^{[3]}$. There is a good correlation between HbA1c, FPG \& PPPG and the risk of developing diabetic complications. HbA1c measurement determines the average level of glycemic control over the previous
$8-12$ weeks and is accepted as a standard for monitoring of chronic hyperglycemia, moreover HbAlc levels along with glucose estimation can be used for diagnosing T2DM ${ }^{[6,16]}$

According to ADA Clinical Practice Guidelines, the recommended target for glycemic control for diabetes is $\mathrm{HbAlc} \leq 7 \%{ }^{[7]}$. Therefore, in the present study HbA1c along with FPG and PPPG was evaluated and it was observed that values of FPG, as well as PPPG were much higher in uncontrolled DM (GpIII) as compared to 
controlled DM suggesting that $\mathrm{HbAlc}$ is a good indicator of plasma F \& PP glucose levels and glycemic control. Present study is also supported by the meta-analysis by Anne et $\mathrm{al},{ }^{[17]}$ who suggested the use of HbAlc levels to diagnose, monitor and treat T2DM.

Diabetic dyslipidemia is a treatable risk factor for subsequent cardiovascular disease. In the present study, TG, total cholesterol (TC), LDL-C and VLDL-C were found to be slightly higher in Gp II and HDL-C was significantly lower than Gp I whereas, in Gp III TG, TC, LDL-C and VLDL-C were significantly higher and HDL-C was significantly lower as compared to Gp I \& Gp II $(p<0.001)$. Thus, it is evident that in uncontrolled T2DM there is significant derangement of lipid profile parameters as compared to controlled diabetes, thereby increasing the risk of complications. Ahmed et al ${ }^{[18]}$, in their study have concluded that serum TC, TG and LDL-C were above normal and serum HDL-C was below normal in diabetics , similar results have also been shown by Gupta et al ${ }^{[19]}$.

High sensitivity C-reactive protein (hsCRP) is an inflammatory protein produced by the liver cells during chronic low grade inflammation, therefore it is a physiological biomarker of sub-clinical inflammation associated with hyperglycemia ${ }^{[20]}$. It is believed that inflammation has a crucial intermediary role in the pathogenesis of T2DM and high hsCRP levels/inflammation have been linked to heart disease ${ }^{[20]}$. In present study, hsCRP levels were significantly increased in Gp II in comparison with Gp I and in Gp III hsCRP levels (5.49 $\pm 1.65 \mathrm{mg} / \mathrm{L})$ were the highest $(\mathrm{p}<0.001)$. Sarinnapakorn et al ${ }^{[21]}$ in their retrospective study of T2DM overweight female patients having BMI $>25 \mathrm{~kg} / \mathrm{m}^{2}$ also reported that hsCRP has positive correlation with $\mathrm{HbAlc}$.

Under normal physiological conditions, there is a balance between the generation of free radicals and the antioxidant defence mechanisms. However, the persistent hyperglycemia in T2DM causes increased production of ROS, which overwhelms the available antioxidant mechanisms. Malondialdehyde is estimated as a marker of lipid peroxidation \& FRAP is used to measure the total antioxidant capacity (TAC) of plasma, which includes the total activity of plasma antioxidants including vitamins and enzymes ${ }^{[5]}$. Pawar et al \& Chavan et al., ${ }^{[22,23]}$ have reported increased MDA levels in diabetic patients as compared to controls. Gupta et al ${ }^{[19]}$, have also reported increased MDA levels in diabetics which were higher in subjects with uncontrolled hyperglycemia having diabetic complications. Gupta et al., ${ }^{[19]}$ and Duman et al., ${ }^{[24]}$ have also reported significant decrease in antioxidant levels in diabetic population. Several other studies have also revealed lower antioxidant and enhanced pro-oxidative status in diabetic conditions ${ }^{[25,26}$.In the present study, MDA levels were higher in diabetics as compared to the control group, \& these were significantly higher in uncontrolled diabetics vs the group with good glycemic control. Further, FRAP was decreased in diabetics and the maximum depletion was seen in uncontrolled as compared to controlled diabetics, Moreover, there is a positive correlation between MDA(lipid peroxidation) and $\mathrm{HbAlc}$; a negative correlation between FRAP(antioxidants) and HbAlc; \& a negative correlation between FRAP and MDA, which reflects a pro-oxidant milieu also indicating that oxidative stress is increased in relation to the degree of hyperglycemia.

\section{Conclusions}

To summarise, T2DM is associated with chronic hyperglycemia, which leads to oxidative stress and associated complications. In the present study, it was observed that there is increased oxidative stress as evident by increased MDA levels and decreased total antioxidant status (FRAP), which can be considered as an early marker for the pathogenesis of late complications of T2DM .The increase in $\mathrm{HbAlc}$ has been found to be associated with decreased levels of FRAP and increased levels of MDA in T2DM .Further, there is a negative correlation between FRAP\& MDA and FRAP \& HbA1c ; \& a positive correlation between MDA and HbA1c . These observations highlight the fact that oxidative stress increases in T2DM in prorortion to the degree of hyperglycemia as evidenced by higher HbAlc levels. Therefore, regular monitoring of glycemic status in T2DM, by estimating glucose and $\mathrm{HbA} 1$ clevels, followed by early intervention in the form of lifestyle modifications may reduce the impact of oxidative stress, which in turn will delay the onset of diabetic complications in the long run.

\section{Acknowledgement}

The authors are thankful to the Department of Biostatistics and Medical Informatics, Sharda University, Uttar Pradesh for statistical analysis.

\section{References}

1. Classification and Diagnosis of Diabetes Mellitus and Other Categories of Glucose Intolerance. Diabetes. 1979; 28(12):1039-1057.

2. Obrosova IG, Van Huysen C, Fathallah L, Cao XC, Greene DA, Stevens MJ. An aldose reductase inhibitor reverses early diabetes-induced changes in peripheral nerve function, metabolism, and antioxidative defense. The FASEB Journal. 2002; 16: 123-125.

3. Maritim AC, Sanders RA, Watkins JB III.Diabetes, oxidative stress and antioxidants: A Review. J Biochem Mol Toxicol 2003; 17:24-38. 
4. Gaweł S, Wardas M, Niedworok E, Wardas P. Malondialdehyde (MDA) as a lipid peroxidation marker. Wiad Lek. 2004; 57(9-10):453-5.

5. Benzie IF, Strain JJ. The ferric reducing ability of plasma (FRAP) as a measure of "antioxidant power": the FRAP assay. Anal. Biochem. 1996; 239: 70-76.

6. Nathan DM, Turgeon H, Regan S. Relationship between glycated haemoglobin levels and mean glucose levels over time. Diabetologia. 2007; 50: 2239-44.

7. American Diabetes Association: Standard of Medical Care in Diabetes-2007. Diabetes Care. 2007; 30; S4- S41.

8. Trinder P. Enzymatic determination of glucose in blood serum. Annals of Clinical Biochem.1969; 6:24-27.

9. Sampson EJ, Baird MA, Burtis CA et al. A coupledenzyme equilibrium method for measuring urea in serum: optimization and evaluation of the AACC study group on urea candidate reference method. Clin Chem 1980; 26: 816-26.

10. Cook JG. Association of clinical Biochemists' Scientific and Technical Committee. Factors influencing the assay of creatinine. Ann Clin Biochem 1975; 12: 219-32.

11. Allain CC. Enzymatic Determination of Total Cholesterol in Serum. Clin Chem. 1974; 20: 470 - 74.

12. Henry JB. Clinical Diagnosis and Management by Laboratory Methods, 18th ed. W.B. Saunders, Philadelphia, 1991; 9:204-211.

13. Burstein M, Scholnick HR, Morgin R. Rapid method for isolation of lipoproteins from human serum by precipitation with polyanions. J Lipid Res 1970; 11:1583-1586.

14. Friedewald WT, Levy RI, Fredrickson DS. Estimation of the concentration of low-density lipoprotein cholesterol in plasma, without use of the preparative ultracentrifuge. Clin Chem. 1972; 18:499-502.

15. Satoh K. Serum lipid peroxide in cerebrovascular disorders determined by a new colorimetric method. Clin Chim Acta1978; 90: 37-43.
16. Zhou J, Li H, Ran X, Yang W, Wang W, et al. Reference values for continuous glucose monitoring in Chinese subjects. Diabetes Care. 2009; 32:1188-93.

17. Anne L, Peters at al. A clinical approach for the diagnosis of diabetes mellitus. JAMA. 1996; 276:1246-52.

18. Ahmed N, Khan J, Siddiqui TS. Frequency of dyslipidaemia in type 2 diabetes mellitus in patients of Hazara division. Ayub Med Coll Abbottabad. 2008;20 (2):51-4.

19. Gupta S, Mehndiratta M, Kalra S, Kalra OP, Shulka R, Gambhir JK. Association of biomarkers of oxidative stress with the risk of chronic kidney disease in type 2 diabetes Mellitus in North Indian population. J Diabetic Complications. 2015; 29: 338-42.

20. Lau DC, Dhillon B, Yan H, Szmitko PE, Verma S. Adipokines: molecular links between obesity and atheroslcerosis. Am J Physiol: Heart Circulation Physiol. 2005; 288: H2031-41.

21. Sarinnapakorn V, Wanicagool W. Association between hsCRP and HbA1cin overweight T2DM female patients. J Med Assoc (Thai). 2013; 96 (Suppl 3): S 54-8.

22. Pawar SM, Tolanur SI, Lakshmi TM, et al. MDA \& FRAP status in Diabetics with Coronary Heart Disease patients. JPBMS. 2011; 4(12):1-4.

23. Chavan VU, Melinkeri RR. Study of protein carbonyl group, nitric oxide and MDA (index of lipid peroxidation) as biomarkers of oxidative stress in type 2 diabetes mellitus. Natl J Community Med. 2013; 4:294-9.

24. Duman BS, Oeztuerk M, Yilmazer S, Hatemi H. Thiols, Malondialdehyde and Total antioxidant status in the Turkish Patients with Type 2 Diabetes Mellitus. Tohoku J Exp Med. 2003; 201(3); 147-155.

25. Ahmed FN, Naqvi FN, Shafiq F. Lipid peroxidation and serum antioxidant enzymes in patients with type 2 Diabetes Mellitus. Ann NY Acad Sci. 2006; 1084: 481-9.

26. Kalaivanam KN, Dharmalingam M,Marcus SR.Lipid peroxidation in Type 2 Diabetes mellitus. Int J Diab Dev Countries.2006;26:30-32.

*Corresponding author:

Prof Jasvinder K Gambhir, Department of Biochemistry, SMS \& R, Sharda University, Knowledge Park-III, Greater Noida, U. P .,India-201306

Phone: +91 9811641277

Email: jassigambhir@yahoo.co.in

Financial or other Competing Interests: None. 